\title{
Quadriceps tendon rupture associated with anabolic steroids and growth hormone: a case report
}

\author{
Engin Özakın¹, Cüneyt Çalışır², Evvah Karakılıç¹, NurdanAcar ${ }^{1}$ \\ ${ }^{1}$ Department of Emergency Medicine, Osmangazi University School of Medicine, Eskişehir, Turkey \\ ${ }^{2}$ Department of Radiology, Osmangazi University School of Medicine, Eskişehir, Turkey
}

\begin{abstract}
Androgenic and human growth hormone derivatives have to potential to increase athletic performance despite increased risk of serious adverse effects. The risk of tendon rupture is very high in the anabolic androgenic steroid users. A 51-year-old male admitted to the emergency department with left knee pain following sport training. He had a history combination of androgenic hormones and insulin growth factor -1 use. Magnetic resonance imaging showed swelling, heterogeneity and partial discontinuity of the quadriceps tendon. Use of performance enhancing drugs has become a serious public health problem. Due to increase of abuse today it is possible to encounter more side effects in the future and has to be considered as a growing public health problem.
\end{abstract}

Eur Res $J$ 2018;4(3):251-253

Keywords: quadriceps tendon rupture, androgenic hormone, growth hormone

\section{Introduction}

Quadriceps tendon rupture is a rare condition in the absence of systemic disease. Some athletes use hormonal drugs to improve their performance, personal appearance and to increase their muscle mass [1]. Especially, the use of androgenic and derivative of biosynthetic human growth hormone has become serious global health problem despite controls and injuries related with them. These drugs showed increased risk of tendon ruptures who are relatively common in bodybuilders [2]. We report partial rupture of quadriceps tendon rupture in a bodybuilder who had taken anabolic steroid and growth hormone for years.

\section{Case Presentation}

Our patient is 51-year-old, healthy, white male, previously professional national class bodybuilders. He ranked first place in his weight class in Turkey national body-building championship, two years ago. He was admitted to our emergency department with left knee pain following sport training. He experienced sudden severe pain in his right knee after attempting front squat $150 \mathrm{~kg}$ of weight. He reported a history combination of androgenic (nandrolone) and insulin growth factor-1 use that he had stopped before 6 months. He had also been previously insulin resistance, cardiac hypertrophy and left biceps tendon rupture (20 years ago). 
On examination he was unable to walk and straight leg raise. He has also hematoma and swelling in left knee. Magnetic resonance imaging (MRI) of the left knee joint was performed using a 3T unit. Sagittal and axial T1-weighted and proton- density weighted images with fat saturation were obtained. MRI showed swelling, heterogeneity and partial discontinuity of the quadriceps tendon (Figure 1). Partial tear of the quadriceps tendon was diagnosed. Immobilization with full extension was recommended.

\section{Discussion}

Use of performance enhancing drugs has become a serious public health problem. The overall lifetime prevalence for use of the androgenic hormones rate was 6.4 percent in men, 1.6 percent in women [3]. Performance enhancing drugs are anabolic androgenic steroids, androstenedione, human growth hormone, erythropoietin, diuretics, creatine and stimulants. Frequently, the anabolic androgenic steroids that body-builders use are synthetic modifications of testosterone. The most commonly used androgens are testosterone, trenbolone and boldenone [4]. They assist athletes by facilitating efforts to gain strength and muscle mass for increased muscular endurance and power. They promote an increased nitrogen concentration in muscle; which promote anabolic state. Usually they can be taken as injections and pills. It is estimated that 1 million men have experienced these drugs [5].

There are many adverse effect of anabolic steroids and some can be serious and mortal. Case reports describe sudden death in young athletes who were taking androgens [6]. The most important and common side effects of anabolic steroids are gynecomastia, infertility, impotence in men [7] and a deeper voice, increased body hair, cliteromegaly, infrequent or absent menstrual periods in women [8]. Both men and women also have increased risk of severe acne, liver abnormalities and tumors, high blood pressure, heart circulatory problems [9], increased aggressiveness [10], psychiatric disorders [11], injection disease such as HIV or hepatitis [12] and decrease serum high density lipoprotein (HDL) and increase low density lipoprotein (LDL) [13].

Human growth hormone is a hormone that has an anabolic effect. Athletes take it to improve muscle mass and performance like testosterone derivatives. It is only administered by injection. Growth hormones like androgenic hormones, has been used, approximately 5 percent of United States high school students report using these [14]. The most common adverse effect related to growth hormone are joint pain, myopathy, carpal tunnel syndrome, impaired glucose regulation, sodium retention, cardiomegaly, high cholesterol and high blood pressure $[15,16]$. Usually the degree and the severity of these side
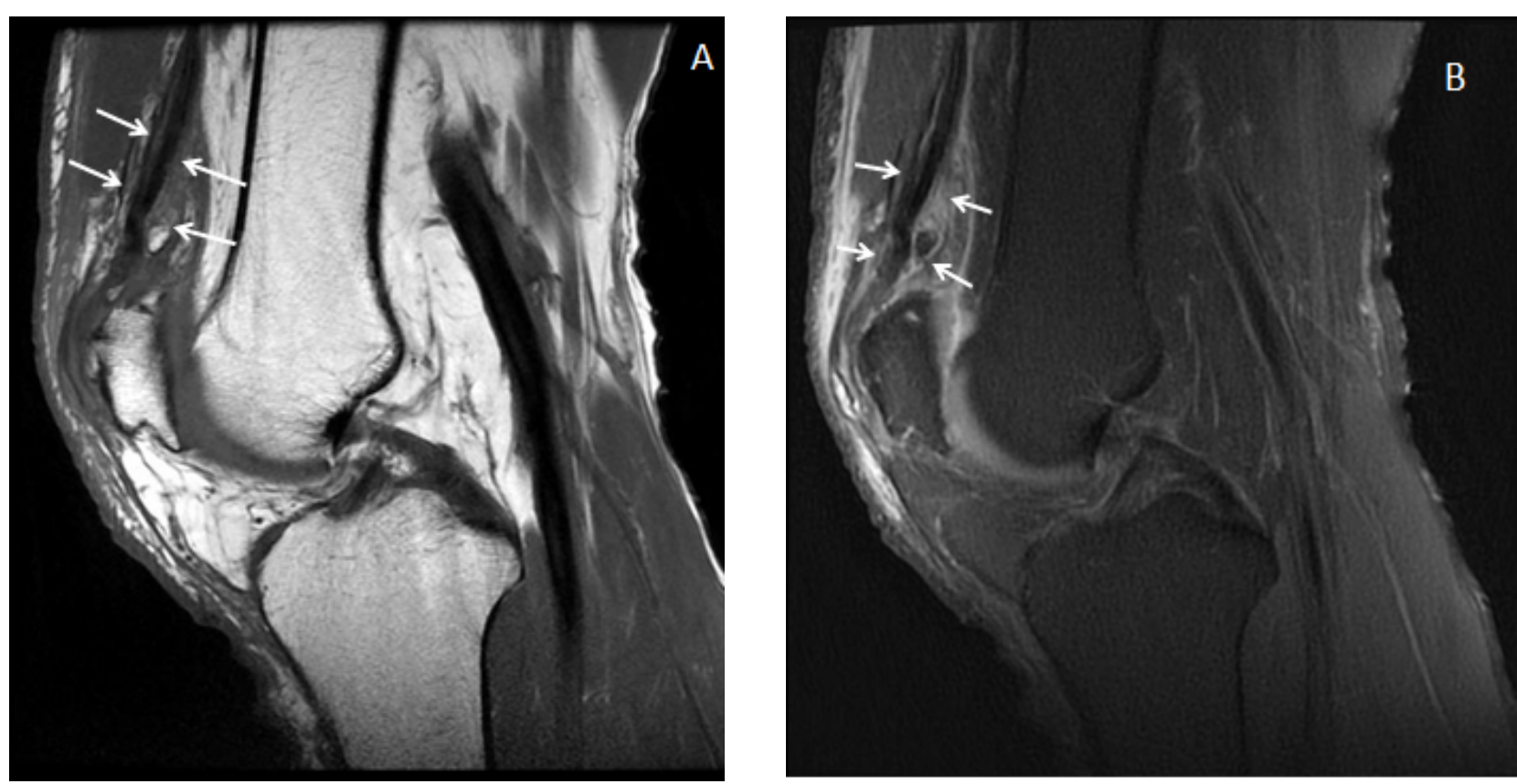

Figure 1. Sagittal T1 weighted image (A) and sagittal proton-density fat suppressed image (B) reveal enlarged and edematous quadriceps tendon and a fluid collection within the tendon (arrows), suggestive of partial rupture of the quadriceps tendon. 
effects are often decrease with the cessation of the drug use. But it should not be forgotten that individuals will respond differently depending on each person's unique body physiology.

Some of the side effects that are associated with steroid use are tendinitis and tendon ruptures [17, 18]. There are several case reports regarding tendon ruptures associated to the anabolic steroids but very few of them are in the quadriceps tendon. The risk of tendon rupture is 9.0 times greater in the anabolic androgenic steroid users. The incidence of lover extremity tendon ruptures is much less than that for upper extremity ruptures. Simultaneous quadriceps rupture occurs commonly between ages 27 and 54 . Quadriceps tendon rupture is usually associated with some chronic diseases like renal failure, diabetes, and gout. In addition, case of performance enhanced drug use have also been reported. The most common cause of quadriceps tendon rupture appears to be sudden contraction of the quadriceps with knees.

\section{Conclusions}

Performance-enhanced drug abuse has a substantial public health problem. The use of androgens, growth hormone and other drugs have an increased adverse effect. Although these drugs are prohibited, their use are very common. Due to increase of abuse today it is possible to encounter more side effects in the future and has to be considered as a growing public health problem.

\section{Informed consent}

Written informed consent was obtained from the patient for the publication of this case report.

\section{Conflict of interest}

The authors declared that there are no potential conflicts of interest with respect to the research, authorship, and/or publication of this article.

\section{References}

[1] Parkinson AB, Evans NA. Anabolic androgenic steroids: a survey of 500 users. Med Sci Sports Exerc 2006;38:644-51.

[2] Kanayama G, DeLuca J, Meehan WP 3rd, Hudson JI, Isaacs S, Baggish A, et al. Ruptured tendons in anabolic-androgenic steroid users: a cross-sectional cohort study. Am J Sports Med 2015;43:2638-44.

[3] Sagoe D, Molde H, Andreassen CS, Torsheim T, Pallesen S. The global epidemiology of anabolic-androgenic steroid use: a meta-analysis and metaregression analysis. Ann Epidemiol 2014;24:383-98.

[4] United States Anti-Doping Agency - Results Management. http://www.usada.org/results/ (Accessed on January 11, 2011).

[5] Buckman JF, Farris SG, Yusko DA. A national study of substance use behaviors among NCAA male athletes who use banned performance enhancing substances. Drug Alcohol Depend 2013;131:50-5.

[6] Hausmann R, Hammer S, Betz P. Performance enhancing drugs (doping agents) and sudden death--a case report and review of the literature. Int J Legal Med 1998;111:261-4.

[7] Rahnema CD, Lipshultz LI, Crosnoe LE, Kovac JR, Kim ED. Anabolic steroid-induced hypogonadism: diagnosis and treatment. Fertil Steril 2014;101:1271-9.

[8] Pope HG Jr, Wood RI, Rogol A, Nyberg F, Bowers L, Bhasin S. Adverse health consequences of performance-enhancing drugs: an Endocrine Society scientific statement. Endocr Rev 2014;35:341-75.

[9] King DS, Sharp RL, Vukovich MD, Brown GA, Reifenrath TA, Uhl NL et al. Effect of oral androstenedione on serum testosterone and adaptations to resistance training in young men: a randomized controlled trial. JAMA 1999;281:2020-8. [10] O'Connor DB, Archer J, Hair WM, Wu FC. Exogenous testosterone, aggression, and mood in eugonadal and hypogonadal men. Physiol Behav 2002; 75:557-66.

[11] Bhasin S, Woodhouse L, Casaburi R, Singh AB, Bhasin D, Berman N, et al. Testosterone dose-response relationships in healthy young men. Am J Physiol Endocrinol Metab 2001;281:E1172-81.

[12] Aitken C, Delalande C, Stanton K. Pumping iron, risking infection? Exposure to hepatitis C, hepatitis B and HIV among anabolic-androgenic steroid injectors in Victoria, Australia. Drug Alcohol Depend 2002;65:303-8.

[13] Thompson PD, Cullinane EM, Sady SP, Chenevert C, Saritelli AL, Sady $\mathrm{MA}$, et al. Contrasting effects of testosterone and stanozolol on serum lipoprotein levels. JAMA 1989;261:1165-8.

[14] Sjöqvist F, Garle M, Rane A. Use of doping agents, particularly anabolic steroids, in sports and society. Lancet 2008;371:1872-82.

[15] Fernandez MM, Hosey RG. Performance-enhancing drugs snare nonathletes, too. J Fam Pract 2009;58:16-23.

[16] Segura J, Gutiérrez-Gallego R, Ventura R, Pascual JA, Bosch J, SuchSanmartín G, et al. Growth hormone in sport: beyond Beijing 2008. Ther Drug Monit 2009;31:3-13.

[17] Sollender JL, Rayan GM, Barden GA. Triceps tendon rupture in weight lifters. J Shoulder Elbow Surg 1998;7:151-3.

[18] Cope MR, Ali A, Bayliss NC. Biceps rupture in body builders: three case reports of rupture of the long head of the biceps at the tendon-labrum junction. $J$ Shoulder Elbow Surg 2004;13:580-2. 